\title{
IA INVESTIGACION
}

\section{de la universidad relacionada con la generación de activos intangibles}

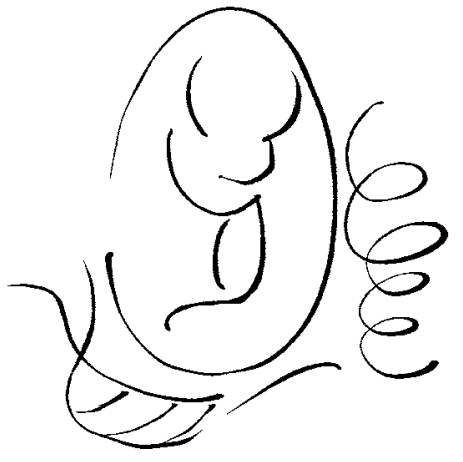

El presente artículo repasa las actividades de investigación que se realizan en la universidad. Comprendiendo las fases de investigación y desarrollo, propone que los desembolsos efectuados en la fase de investigación no generen activos intangibles y se reconozcan como gastos en el momento que se produzcan, en tanto que los desembolsos efectuados en la fase de desarrollo se han de constituir en activos intangibles de conformidad con la Norma Internacional de Contabilidad. NIC 38 Activos Intangibles.

Palabras clave: investigación y desarrollo, activos tangibles, activos intangibles, patrimonio.

\section{1) Marco conceptual y legal de la investigación}

La universidad tiene como función la investigación ${ }^{1}$, y la obligación de publicar en sus portales electrónicos la información correspondiente a proyectos de investigación y gastos que genere ${ }^{2}$.

La investigación constituye una función esencial y obligatoria de la universidad, que la fomenta y realiza respondiendo a través de la producción de conocimiento y desarrollo de tecnologías de acuerdo a las necesidades de la sociedad, con especial énfasis en la realidad nacional ${ }^{3}$. La universidad propiciará, estimulará y realizará la investigación como función básica dando preferente atención a los problemas de interés regional y nacional ${ }^{4}$.

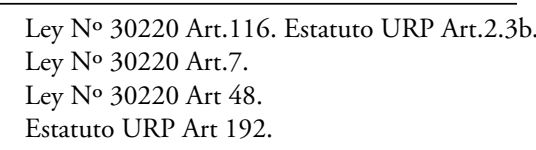

Las publicaciones que hayan sido producto de investigaciones financiadas por la universidad reconocen la autoría de sus realizadores. En cuanto al contenido patrimonial, la universidad suscribe un convenio con el autor para la distribución de las utilidades en función de los aportes entregados. En los demás aspectos vinculados con esta materia se aplica la legislación vigente sobre derechos de autor ${ }^{5}$.

La universidad cooperará con el Estado, realizando, por iniciativa propia o por encargo de este, de acuerdo con sus posibilidades, proyectos de investigación que contribuyan a atender los problemas de la región o del país 6.

La universidad incluirá dentro de su presupuesto una partida destinada a financiar las actividades de investigación. Esta, a su vez, estará contenida en el Programa Anual de Financiamiento de Proyectos de Investigación ${ }^{7}$.

La universidad brindará apoyo académico y económico para la publicación de las investigaciones.

La investigación se refiere a una de las funciones sustantivas de la universidad que permite la generación y transferencia del conocimiento. Generalmente está asociada con los estudios de posgrado y es una de

\begin{tabular}{ll}
\hline 5 & Ley No 30220 Art 53. \\
6 & Estatuto URP Art.194. \\
7 & Estatuto URP Art.196. \\
8 & Estatuto URP Art.201.
\end{tabular} 
las áreas de indispensable análisis en los procesos de evaluación y de acreditación?

2) Importancia y obligatoriedad de la aplicación de las normas internacionales de información financiera - NIIFs en el Perú ${ }^{10}$

Siendo un ente económico, desde el momento de su constitución se llevan a cabo actos o transacciones económicas con el propósito de alcanzar los fines que constituyen su objeto social.

Los referidos actos o transacciones que tienen consecuencia de contenido económico afectan en el activo, el pasivo o el patrimonio de la unidad económica de forma directa y concreta.

Con la globalización continuada de los mercados de productos, servicios y capital, ha surgido la necesidad creciente de aumentar la transparencia y la comparabilidad de la información financiera a través de los países adoptando un conjunto único de estándares globales de contabilidad e información financiera denominadas Normas Internacionales de Información Financiera -NIIFs (IFRS por su sigla en inglés). Las NIIFs, además de los ahorros importantes en los costos, también ofrecen las siguientes ventajas:

- Políticas de contabilidad y de información financiera estandarizadas y mejoradas que benefician de manera directa a los accionistas y a los analistas que buscan información de alta calidad y consistente para evaluar a las empresas más allá de las fronteras.

- Uso más eficiente y disponibilidad de recursos, al ofrecer la oportunidad para desarrollar procesos de contabilidad centralizados mediante un enfoque de servicios compartidos.

- Controles mejorados. Las NIIFs permiten mayor control sobre la presentación de reportes estatutarios, reduciendo, por lo tanto, los riesgos relacionados con las sanciones y los problemas de cumplimiento a nivel local.

- Mejor administración del efectivo debido a que puede tener efectos importantes en los dividendos en efectivo, permitiendo estándares consistentes a través de los países con lo cual puede mejorar la planeación del efectivo.

9 Modelo de Calidad para la Acreditación de las Carreras Profesionales Universitarias y Estándares para la Carrera de Educación.

10 Globalización Contable. Guía para la adopción de los IFRS.Deloitte-Perú.
La investigación trata de una de las funciones sustantivas de la universidad que permite la generación y transferencia del conocimiento. Generalmente está asociada con los estudios de posgrado y es una de las áreas de indispensable análisis en los procesos de evaluación y de acreditación.

En nuestro país, las Normas Internacionales de Información Financiera, NIIFs, son adoptadas y oficializadas por el Consejo Normativo de Contabilidad, que es el ente con atribuciones de emitir o aprobar las normas de contabilidad para las entidades económicas del sector privado en virtud de lo dispuesto en el literal b) del artículo $10^{\circ}$ de la Ley No 28707 , Ley General del Sistema Nacional de Contabilidad.

\section{3) Norma Internacional de Contabilidad - NIC 38 Activos intangibles.}

\section{Definición de activo ${ }^{11}$}

Un activo es un recurso controlado por la entidad como resultado de sucesos pasados u ocurridos del cual se espera obtener, en el futuro, beneficios económicos. El potencial de beneficios económicos de un activo puede ser:

a) De tipo productivo, constituyendo parte de las actividades de operación de la entidad, (inventarios).

b) Puede también tomar la forma de convertibilidad en efectivo u otras partidas equivalentes, (cuentas por cobrar).

c) Bien de capacidad para reducir pagos en el futuro, tal y como cuando un proceso alternativo de manufactura reduce los costos producidos (maquinarias).

$\overline{11 \text { Marco conceptual de la Información Financiera. }}$ 


\section{Definición de activos intangibles ${ }^{12}$}

La Norma Internacional de Contabilidad - NIC 38 Activos Intangibles, versión 2014, vigente a partir del 01.01.2016, define los activos intangibles, como aquellos activos identificables de carácter no monetario y sin apariencia física.

Con frecuencia, las entidades emplean recursos o incurren en pasivos para la adquisición, desarrollo, mantenimiento o mejora de recursos intangibles tales como el conocimiento científico o tecnológico, el diseño e implementación de nuevos procesos o nuevos sistemas, las licencias o concesiones, la propiedad intelectual, los conocimientos comerciales o marcas (incluyendo denominaciones comerciales y derechos editoriales).

Otros ejemplos comunes de partidas que están comprendidas en esta amplia denominación son los programas informáticos, las patentes, los derechos de autor, las películas, la lista de clientes, los derechos por servicios hipotecarios, las licencias de pesca, las cuotas de importación, las franquicias, las relaciones comerciales con clientes o proveedores, la lealtad de los clientes, las cuotas de mercado y los derechos de comercialización.

\section{4) La investigación de la universidad relacionada con la generación de activos intangibles}

La NIC 38 Activos Intangibles, establece que investigación es todo aquel estudio original y planificado emprendido con la finalidad de obtener nuevos conocimientos científicos o tecnológicos; y que desarrollo es la aplicación de los resultados de la investigación o de cualquier otro tipo de conocimiento científico a un plan o diseño en particular para la producción de materiales, dispositivos, productos, métodos, procesos o sistemas nuevos o sustancialmente mejorados, antes del comienzo de su producción o utilización comercial.

\section{Activos intangibles generados internamente}

Para evaluar si un activo intangiblegenerado internamente cumple los criterios para su reconocimiento, la entidad clasificará la generación del activo en:

12 NIC 38, párrafo 8. a) La fase de investigación.

b) La fase de desarrollo.

Si la entidad no fuera capaz de distinguir la fase de investigación de la fase de desarrollo en un proyecto interno para crear un activo intangible, tratará los desembolsos que ocasione ese proyecto como si hubiesen sido soportados solo en la fase de investigación.

\section{Fase de investigación}

Son ejemplo de actividades de investigación:

a) Las actividades dirigidas a obtener nuevos conocimientos.

b) La búsqueda, evaluación y selección final de aplicaciones de resultados de la investigación u otro tipo de conocimientos.

c) La búsqueda de alternativas para los materiales, aparatos, productos, procesos, sistema o servicios.

d) La formulación, diseño, evaluación y selección final de posibles alternativas para materiales, dispositivos, productos, procesos, sistemas o servicios que sean nuevos o se hayan mejorado.

En la fase de investigación de un proyecto interno, la entidad no puede demostrar que exista un activo intangible que pueda generar probables beneficios económicos en el futuro. Por lo tanto, los desembolsos correspondientes se reconocerán como gastos en el momento en que se produzcan.

\section{Fase de desarrollo}

Son ejemplos de actividades de desarrollo:

a) El diseño, construcción y prueba, anterior a la producción o utilización de modelos y prototipos.

b) El diseño de herramientas, troqueles, modelos y plantillas que impliquen tecnología nueva.

c) El diseño, construcción y prueba de una alternativa elegida para materiales, dispositivos, productos, procesos, sistemas o servicios que sean nuevos o que se hayan mejorado. 
En la fase de desarrollo de un proyecto interno, la entidad puede, en algunos casos, identificar un activo intangible y demostrar que el mismo puede generar probables beneficios económicos en el futuro. Esto se debe a que la fase de desarrollo en un proyecto cubre etapas más avanzadas que la fase de investigación.

Un activo intangible surgido de la fase de desarrollo en un proyecto interno se reconocerá como tal si, y solo si, la entidad puede demostrar los extremos siguientes:

a) Técnicamente, es posible completar la producción del activo intangible de forma que pueda estar disponible para su utilización o su venta.

b) Su intención de completar el activo tangible en cuestión para usarlo o venderlo.

c) Su capacidad para utilizar o vender el activo intangible.

d) La forma en que el activo intangible vaya a generar probables beneficios económicos en el futuro. Entre otras cosas, la entidad debe demostrar la existencia de un mercado para la producción que genere el activo intangible o para el activo en sí, o bien, en el caso de que vaya a ser utilizado internamente la utilidad del mismo para la entidad.

e) La disponibilidad de los adecuados recursos técnicos, financieros o de otro tipo, para completar el desarrollo y para utilizar o vender el activo intangible.

f) Su capacidad para medir, de forma fiable, el desembolso atribuible al activo intangible durante su desarrollo.

\section{Costo de un activo intangible generado internamente}

El costo de un activo intangible generado internamente será la suma de los desembolsos incurridos desde el momento en que se cumple las condiciones siguientes:

a) Es probable que los beneficios económicos futuros que se han atribuido al mismo fluyan a la entidad.

b) El costo del activo puede ser medido de forma fiable.

Los desembolsos sobre un activo intangible reconocidos inicialmente como gastos del periodo no se reconocerán posteriormente como parte del costo de un activo intangible.

El costo de un activo intangible generado internamente comprenderá todos los costos atribuibles necesarios para crear, producir y preparar el activo para que pueda operar de la forma prevista por la gerencia. Son ejemplos de costos atribuibles directamente:

a) Los costos de materiales y servicios utilizados o consumidos en la generación del activo intangible.

b) Los costos de las remuneraciones a los empleados derivados de la generación del activo intangible.

c) Los honorarios para registrar los derechos legales.

d) La amortización de patentes y licencias que se utilizan para generar activos intangibles.

No son componentes del costo de los activos intangibles generados internamente los siguientes conceptos:

a) Los gastos administrativos de venta u otros gastos indirectos de carácter general, salvo que su desembolso pueda ser directamente atribuido a la preparación del activo para su uso.

b) Las ineficiencias identificadas y las pérdidas operativas iniciales en las que se haya incurrido antes de que el activo alcance el rendimiento normal planificado.

c) Los desembolsos de formación del personal que ha de trabajar con el activo. 
5) Ilustración de la fase de investigación y de la fase de desarrollo de activos intangibles generados internamente.

\section{Enunciado}

Una entidad está desarrollando un nuevo proceso productivo. Durante el ańo 2015, los desembolsos realizados fueron de 1,000 unidades monetarias, de las cuales 900 fueron reportadas antes del 1 de diciembre de 2015. La entidad es capaz de demostrar que al 1 de diciembre de 2015 el proceso productivo cumplía los criterios para su reconocimiento como activo intangible.

Se estima que el importe recuperable del conjunto de conocimiento incorporados en el proceso es de 500 unidades monetarias (considerando en el cálculo del mismo los desembolsos futuros de efectivo para completar el desarrollo del proceso productivo antes de poder ser utilizado).

\section{Reconocimiento}

Los desembolsos por importe de 900 unidades monetarias en los que se incurrió antes del 1 de diciembre de 2015, se reconocerán como gastos del período, puesto que los criterios de reconocimiento no se cumplieron hasta esa fecha.

Al final de 2015, se reconocerá el proceso productivo como un activo intangible, con un costo de 100 unidades monetarias (igual a los desembolsos realizados desde el momento en que se cumplieron los criterios para el reconocimiento, esto es, desde el 1 de diciembre de 2015).

Durante el año 2016, los desembolsos realizados han sido por importe de 2,000 unidades monetarias, siendo el costo del proceso productivo de 2,100 unidades monetarias (100 por desembolsos reconocidos al final de 2015, más las 2,000 u.m. generadas en 2016).

Al final del ejercicio 2016 la entidad reconocerá una pérdida por deterioro del valor, por un importe de 200 unidades monetarias, con el fin de ajustar el importe en libro antes del deterioro de su valor (que eran 2,100 u.m., hasta alcanzar su importe recuperable (que es de 1,900 u.m.). La entidad podrá revertir esta pérdida por deterioro de su valor, en un período posterior, siempre que se cumplan los requisitos para su reversión, según se establece en la Norma Internacional de Contabilidad 36, Deterioro del valor de los activos.

\section{Desembolsos que se reconocen como gastos en un activo intangible}

En algunos casos se incurre en desembolsos para suministrar beneficios económicos futuros a una entidad, pero no se adquiere ni se crea ningún activo intangible ni otro tipo de activo que pueda ser reconocido como tal. Ejemplos de desembolsos que se reconocen como gasto en el momento en que se incurre en ellos son:

a) Gastos de establecimiento.

b) Gastos de actividades formativas.

c) Gastos en publicidad y otras actividades promocionales.

d) Gastos de reubicación o reorganización de una parte o la totalidad de la entidad.

\section{Vida útil del activo intangiblegenerado internamente}

Un activo intangible con una vida útil finita se amortiza, mientras que un activo intangible con una vida útil indefinida no se amortiza.

La amortización se distribuirá sobre una base sistemática a lo largo de la vida útil y comenzará cuando el activo intangible se encuentre en la ubicación y en las condiciones necesarias para que pueda operar de la forma prevista.

La entidad comprobará si un activo intangible con una vida útil indefinida ha experimentado una pérdida por deterioro del valor comparando su importe recuperable con su importe en libros.

\section{a) Anualmente.}

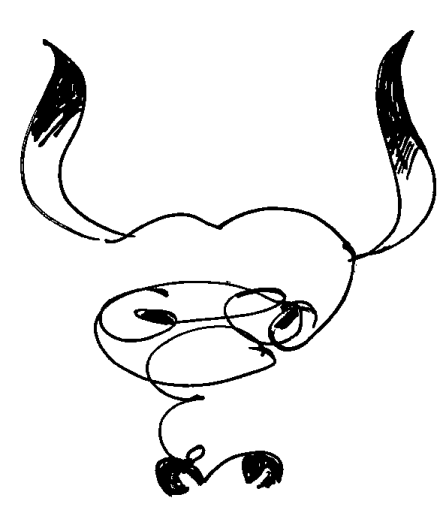

b) En cualquier momento en el que existe un indicio de que el activo puede haber deteriorado su valor.

\section{Información a revelar}

La entidad revelará el importe agregado de los desembolsos por investigación y desarrollo que se hayan conocido como gastos durante el período. 
Presentación al Estado de la Situación Financiera de Activos no Corrientes

Activos Intangibles (neto)*

*Valor histórico

(-) Amortización acumulada

\section{6) Caso de la creación de un nuevo producto}

La entidad acordó crear un nuevo juguete electrónico. La fase de investigación comprende la composición material, forma, color característico y otros del nuevo juguete solar que culmina con el resultado de la investigación de lo que sería el nuevo producto. El desembolso asciende a S/.20,000 más IGV S/.3,600.

Luego del análisis del informe de investigación y la viabilidad del proyecto, se procede al diseño, construcción y prueba del prototipo, como fase de desarrollo para lo cual se invierte la suma de $S / .30,000$ más IGV S/.5,400.
En el caso planteado los desembolsos de la fase de investigación son gastos y se presentará en el Estado de Resultados como gastos del período por $S / .20,000$ y los desembolsos de la fase de desarrollo es activo y se presentará en el Estado de Situación Financiera como activos intangibles.

\section{Estado de resultados (parcial)}

Ingresos de actividades ordinarias

(-) Costo de venta

Ganancia bruta

Gastos del período*

Estado de situación financiera (parcial)

\section{Activos no Corrientes}

Activos Intangibles **

*Fase de Investigación

${ }^{* *}$ Fase de Desarrollo

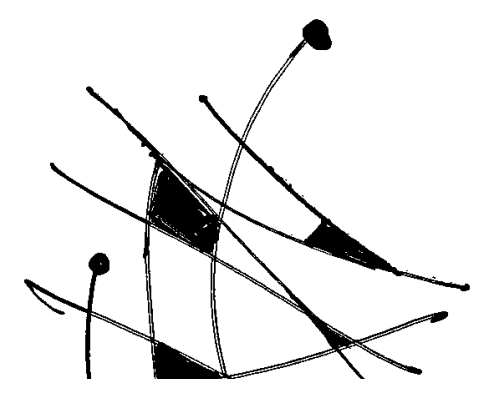

